\title{
Adaptation of Gratitude Questionnaire-6 (GQ-6) in Indonesian Context
}

\author{
Dhanifa Veda Grimaldy ${ }^{1}$, Handrix Chris Haryanto ${ }^{2}$ \\ 1,2Department of Psychology, Universitas Paramadina \\ Submitted 11 October 2018 Accepted 31 July 2019 Published 20 April 2020
}

\begin{abstract}
Adaptation of a psychological instrument is essential due to cultural difference and context. This study aimed to adapt the Gratitude Questionnaire-6 (GQ-6) in an Indonesian context. The initial steps included back-to-back translation, focus group discussion, expert judgements, and pilot study. From this procedure, five additional items were added to the original GC- 6 . The eleven final items were tested to 404 undergraduate students aged 18-24 years-old from several universities in Jakarta. The reliability test, the internal consistency, was examined by the Cronbach's alpha coefficient, while the validity test, construct validity, was examined using exploratory factor analysis (EFA). The result of analysis showed good validity and reliability (Cronbach's alpha: 0.789). This study concluded that 11-item gratitude questionnaire consistently measured gratitude in adolescents based on two factors: appreciation to the constant experience of life and appreciation towards individuals that take part in one's life.
\end{abstract}

Keywords : adolescents; gratitude; gratitude questionnaire-6 (GQ-6)

The Oxford English Dictionary defines gratitude as feeling grateful and wanting to express your thanks. Gratitude is considered as social kindness, wanted and needed by society that relates to the wellbeing of personal, interpersonal, and social scale (Wang, Wang, \& Tudge, 2015). Gratitude is defined as an emotion, attitude, (McCullough, Emmons, \& Tsang, 2003).

According to Tsang (2006), gratitude is expressed towards peers, object, or a good deed that an individual has received that resulted in positive emotions. McCullough, Emmons, dan Tsang (2002) stated that each individual holds different tendencies in feeling gratitude. Four facets

\footnotetext{
${ }^{1}$ Address for corespondence:

dhanifa.grimaldy@yahoo.com
}

could differentiate those tendencies: intensity, frequency, span, and density. These facets refer to the intensity and frequency of an individual's feeling, the quantity of their gratitude, and the range of experience in feeling gratitude (McCullough et al., 2002).

Gratitude could be expressed and experienced since an early age. As people grow older and gain more experience, gratitude starts to develop. Wang, et al (2015) shows that age factor could influence gratitude, expression of gratitude will increase by the increase of age. Children in different age range will express gratitude also in many different ways (Wang et al, 2015).

For adolescents, gratitude is associated with positive emotions, such as pride, sanguine, forgiveness, and being 
motivated (Froh, Yurkewicz, \& Kashdan, 2009). Gratitude positively impacts adolescents, enabling them to contribute to their surrounding environment (Froh, Bono, \& Emmons, 2010). It predicts social integration and mediates between one's proportionate behavior and life satisfaction. Considering the benefit it delivers, there is a need to come up with a scale to measure gratitude for adolescents (Froh et al., 2010).

In Indonesia, adolescents owns various profiles due to the variety of ethnic, culture, socio-economic levels and education (Sarwono, 2007). According to Sarwono (2007) adolescents, in the Indonesian context, are unmarried individuals aged between 11 until 24 years old with several other considerations: (1) Physical criteria, secondary sexual characteristics began to appear by the age of eleven. (2) Social criteria, according to customs and religion, puberty happens by the age of eleven, leading children to be considered as adults. (3) Psychological criteria, referring to the genital phase from the psychosexual development by Freud, the peak of cognitive development by Piaget, along with self identity by Erikson. (4) 24 years is the maximum age for an individual to be classified as an adolescent, with criteria where individuals with that age limit cannot meet social or psychological maturity requirements. It can be concluded that Indonesian adolescents are those aged between 11 to 24 years old who are unmarried.

\section{The Gratitude Questionnaire-6 (GQ-6)}

Gratitude Questionnaire-6 (GQ-6) is one of the gratitude instrument designed for adult samples, however, several studies have also applied it for adolescent samples such as Froh, et al. (2011). Froh et al (2011) measured the reliability and validity of
GQ-6 on children and adolescents aged between 10 - 19 years who are mainly Caucasians. Findings from the previous study found that GQ-6 showed good reliability (Cronbach's alpha: >0.70) and good convergent validity. The convergent validity is seen from correlating the GQ-6 value with other gratitude scales such as Gratitude, Resentment, Appreciation TestShort Form (GRAT-Short Form) and Gratitude Adjective Checklist (GAC). The convergent validity test found a positive correlation between those measurement tools.

Neto (2007) conducted research about gratitude using GQ-6. The research involved 152 Portuguese college students ranging from $18-26$ years old (Caucasian). The result showed that the GQ-6 achieved good reliability in measuring the gratitude level of Portuguese college students (Cronbach's alpha: 0.75).

Furthermore, Langer, Ulloa, AguilarParra, Araya-Véliz, dan Brito (2016) translated the scale into Spanish and adapted the respondents to include adolescents and adults. For the adolescents (age 12-20 years old), the research concluded a 5-item version of the scale showed better reliability (Cronbach's alpha: 0.726), namely by removing item number six. The research on adult respondents (Mage: 37.6 years old), found that the original version of GQ-6 is suitable (Cronbach's alpha: 0.832).

Yüksel and Oğuz Duran (2012) adapted GQ-6 into Turkish by testing its' reliability and validity in measuring the level of gratitude of Turkish college students (age: 20 years old). The result of the research showed that the Turkish CQ-6 had better construct validity when it eliminated item number six. It also achieved good internal consistency (Cronbach's 
alpha: 0.77) and test-re-test correlation (0.66).

Chen, Chen, Kee, and Tsai (2009) research translated Gratitude Questionnaire-6 (GQ-6) into Chinese and examined its' validity and reliability on Taiwanese college students. The result of the research showed that the Chinese GQ-6 has good reliability (Cronbach's alpha: 0.80). Similar to previous findings, the factor analysis indicates that item number six is insignificant. Hence, item number six was eliminated, leaving the Chinese GQ with five items. Furthermore, the confirmatory factor analyses result shows that the fiveitem model holds a better validity compared to the six items. The construct validity is seen from the total correlation score with happiness $(\mathrm{r}=0.31, \mathrm{p}<0.001)$, optimism $(r=0.28, p<0,001)$, agreeableness $(r=0.42, p<0.001)$, extraversion $(\mathrm{r}=0.11, \mathrm{p}<0.001)$, and neuroticism $(\mathrm{r}=$ $0.4, \mathrm{~ns})$.

Similar to the research conducted by Chen, Chen, Kee, and Tsai in 2009, Oriza and Menaldi (2010) translated and validated the Indonesian version of GQ-6 by testing it on 37 Indonesians, age ranging from 21 - 55 years old. The study finding indicates that the gratitude scale achieved a Cronbach's alpha of 0.75 with eight items.

GQ-6 is a unifactorial scale of gratitude (McCullough et al., 2002) that consists of four facets: intensity, frequency, span, and density. McCullough et al. (2002) used the term facet for elements in gratitude due to them being dependent on each other. The research (McCullough et al., 2002), showing an exploratory factor analysis towards 39 items, indicates the formation of one significant factor that explains $27 \%$ of the total item variance with ten other factors formed. However, those factors only contribute $7 \%$ of the total item variance leading to the research only using six good items in the first factor. Furthermore, confirmatory factor analysis was conducted towards the six items by confirming one formed item (McCullough et al., 2002)

The research conducted by Chen, et al. (2009) using confirmatory factor analysis confirmed that the five-item model of GQ6 that consists of one factor has a better validity than the six-item model. Furthermore, the exploratory factor analysis on GQ-6 by Yüksel and Oğuz Duran (2012) showed that there are two factors, each explaining $44.42 \%$ and $18.64 \%$ variance respectively. The second factor only consists of one item which is item number six. Hence, for the next confimatory factor analysis only using five-items, item number six was excluded. The result of confirmatory factor analsysis with fiveitems showed the formation of one significant factor that explains $53.27 \%$ of the total variance.

In several research in Indonesia using Gratitude Questionnaire-6 (GQ-6) by measuring the existing facet as a factor or dimension so that categorize six-item Gratitude Questionnaire-6 (GQ-6) into the facets. The research by Hafix (2018) categorize six item Gratitude Questionnaire-6 (GQ-6) into four existing facet, they are intensity that is described by item number 1,3, and 5; frequency in item number 6; span in item number 2; density in item number 4 . On the other hand, Angelia (2016) categorized GQ-6 into four dimension: intensity (item 5, 7), frequency (item 6), span (item 1, 2, 3), and density (item 4, 8). In the research by Angelia (2016) the confirmatory factor analysis showed that the gratitude scale does not fully fit with one factor, indicating that there is a need for modification towards that particular scale model. 
From the aforementioned studies, it can be seen that the GQ-6 factor analysis achieved diversed findings. Therefore, it remains to be substantial reasons to conduct an exploratory factor analysis in Indonesia. Exploratory factor analysis is suitable to be conducted when a researcher seeks to identify unsuitable items, modifying, repairing, or removing them to increase consistency (Osterlind, 2010). Previous studies that showed good reliability for GQ-6 highlighted that some of them added or deducted particular items to ensure that it is culturally relevant to the respondents. This is in line with Morgan, Gulliford, dan Kristjánsson (2014) that posits a possibility that concept of gratitude could differ due to cultural differences.

According to Naito dan Washizu (2015) exploring the role of cultural differences on gratitude remains to be an important issue to be investigated. Wang, et al. (2015) showed that cultural factor could influence gratitude, namely that Chinese children and adolescent expressed more gratitude compared to those from America. Social context and cultural values can influence the amount as well as expression of gratitude. This is due to the different process of socialization in particular society, resulting in different attitude from their people (Wang et al, 2015).

\section{Adaptation of instrument}

Cross cultural adaptation is a process of translating items by adjusting it to the cultural context where the measurement tool would be applied (Beaton, Bombardier, Guillemin, \& Ferraz, 2000). Adaptation of a psychological instrument is essential because it cannot be assumed to hold the same psychometric quality if it only went through language translation (Gudmundsson, 2009).
According to Gudmundsson (2009) there are eight steps of translating and adapting a psychology instrument. We begin by deciding the psychological instrument or test, selecting qualified translators, selecting experts in psychology instruments, and choosing the correct translation methods. There are two methods of translation, those are backtranslation and independent translations. The next step is to apply the correct step of adaptation, applying the correct method to know the bias of the translated and adapted instrument, apply the, the correct procedure in the pilot study and the last step is to conduct the appropriate validity test.

Reliability refers to the extent to which the measurement tool can be trusted (Suryabrata, 1999). According to Kaplan and Saccuzzo (2005) reliability refers to the accuracy, consistency, or relevance of the repetition of test results. Reliability is the level of test scores regardless of measurement errors (Kaplan \& Saccuzzo, 2005). Anastasi and Urbina (1997) stated that reliability refers to the consistency of scores obtained by individuals when they are retested on different occasions, with a group of different equivalent points, or under different testing conditions. Reliability refers to the consistency of measurement results and the accuracy of measurement. Reliability is one of the main characteristics that shows whether an instrument is considered to be a good tool (Azwar, 1995). Kaplan and Saccuzzo (2005) mentioned the recommended reliability coefficients of 0.70 and 0.80 for research purposes. Kaplan and Saccuzzo (2005) as well as Anastasi and Urbina (1997) also revealed that the desired reliability coefficient is between 0.80 to 0.90 . 
Validity test is used to examine the degree of accuracy of a measurement tool. Anastasi and Urbina (1997) stated that validity considers whether the measurement tool could correctly measure what is meant to be measured. According to Kaplan and Saccuzzo (2005), the validity refers to the appropriateness between the test score towards the quality of the one being measured. Further, validity is the relevancy of the substance of the questions arranged can deliver information regarding to construct that is to be measured (Azwar, 1995). According to Azwar (1999), the purpose of the validity test is to test the measurenment tools.

\section{Method}

\section{Procedure}

The first step of adapting the GQ-6 is translation. The process of translating GQ6 into Indonesian was done by a sworn translator. After obtaining items in Indonesian, the researcher conducted a back translate, namely translating the Indonesian items back to English, a process which was also conducted by a sworn translator.

Next, expert judgments was conducted to examine the appropriateness of the item and the result of the translation. Based on the expert judgment, several GQ6 items were revised, turning it into eight items.

A focus group discussion was then conducted with participants to ensure that the scale is understandble. Respondents in the focus group discussion were university students located in Jakarta. Five individuals from differing religions (i.e., Islam, Christian, Catholics, Hinduism, Buddhism) and ethnicities (i.e., Sundanese, Ambonese, Javanese, Balinese, Malay) participated in the focus group discussion.
The result of the FGD depicted that Indonesian adolescents' source of gratitude is not only towards other humans but also to God, the universe, and all the good and bad experiences in life. As a result, additional items were added to the GQ-6. These additional items were discussed further through another round of expert judgment.

Next, Pilot study was conducted using the 11-item gratitude questionnaire. The additional items were obtained from the expert judgment and FGD result. The pilot study highlighted that the eleven items tested to have fulfilled the standard items.

\section{Respondent}

To examine the reliability of adapted GQ6 , this study involved university students aged between 18-24 years old in Jakarta. The process of obtaining the samples was conducted using convenience sampling based on the availability and willingness of the samples to become respondents.

The total of 404 respondents consist of 404 respondents consisting of 101 male $(25 \%)$ and 303 female $(75 \%)$. The religious diversity of the participants was as followed: Islam (78\%), Christian (11,1\%), Catholics $(5.9 \%)$, Confucianism (2.0\%), Hinduism (1.5\%), Buddhism (1.0\%) and others $(0.5 \%)$. There were five ethnicities with the largest percentage of Javanese $(41.3 \%)$, Sundanese $(19.3 \%)$, Betawinese $(8.4 \%)$, Bataknese $(7.4 \%)$, and Minangnese $(4.7 \%)$.

\section{Data analysis}

The current research examined the reliability of the scale through its' internal consistency. Internal consistency was reliability based on data obtained from one conducted test or granting attitude scale to a group of respondents (Azwar, 1995). We 
used the Cronbach's alpha coefficient to determine the internal consistency of the scale. According to Azwar (2012), the construct validity shows whether the measurement result obtained from the test items have a high correlation with the theoretical construct that will be the basis of drafting the test. Exploratory factor analysis (EFA) was applied to investigate the factors that create a construct by seeing the largest variance with the least number of factor (Azwar, 2012).

\section{Results}

Result of the reliability analysis with Cronbach's alpha coefficient, $\alpha=0.879$. Item-total correlation was between 0.517 0.655 . This indicated a good reliability as Kaplan \& Saccuzzo (2005) stated that, for research purposes, the recommended coefficient reliability is 0.70 and 0.80 .

Exploratory factor analysis (EFA) was conducted with the aim to uncover underlying factors of a construct by finding or seeking the largest variance with the least amount of factors (Azwar, 2012).

This research followed the eigenvaluegreater-than-one rule (Kaiser, 1960) to determine the number of factors that should be included to the model. From Table 1, it can be seen that there are two factors with an eigenvalue greater than one. These two factors account for $59.2 \%$ of the total variance of the scale.

Table 2 shows the rotated component matrix by the varimax method of the two- factor solution. Factor one consists of item $4,5,6,7,8$, and 9. Meanwhile, factor two consists of item 1, 2, 3, 10, and 11. Factor one refers to gratitude as an appreciation towards the constant experience of life. Factor two refers to gratitude as an appreciation towards individuals in various parts of life. Table 3 shows item distribution and names of factors.

\section{Discussion}

The Gratitude Questionnaire-6 (GQ-6) consists of one factor, known as unifactoral (McCullough et al., 2002) which consists of 4 facet or aspects, namely intensity, frequency, span, and density. Intensity refers to the extent to which an individual feels grateful. Frequency refers to how often an individual feels grateful, for example in a day how much does an individual feels grateful. Span refers to the number of events that leads an individual to experience gratitude within a certain period. Density refers to the number of objects of gratitude emotions.

The GQ-6 originally consists of six items. In this research, five additional items were added to the Gratitude Questionnaire-6 (GC-6), resulting in eleven final items. Five additional items were obtained from revising the items based on the writing conventions of items according to Azwar (1999) and focus group discussion, which was later evaluated through expert judgment.

Table 1.

Total Variance Explained

\begin{tabular}{ccccc}
\hline \multirow{2}{*}{ Component } & \multicolumn{2}{c}{ Initial Eigenvalues } & \multicolumn{2}{c}{ Rotation Sums of Squared Loadings } \\
\cline { 2 - 5 } & Total & \% of Variance & Total & \% of Variance \\
\hline 1 & 5.219 & 47.447 & 3.412 & 31.015 \\
2 & 1.309 & 11.899 & 3.116 & 28.331 \\
\hline
\end{tabular}


Table 2.

Tabel Rotated Component Matrix

\begin{tabular}{ccc}
\hline & \multicolumn{2}{c}{ Component } \\
\cline { 2 - 3 } & $\mathbf{1}$ & $\mathbf{2}$ \\
\hline Item 1 & 0.185 & $\mathbf{0 . 7 7 1}$ \\
Item 2 & 0.248 & $\mathbf{0 . 7 9 8}$ \\
Item 3 & 0.243 & $\mathbf{0 . 6 4 6}$ \\
Item 4 & $\mathbf{0 . 7 4 8}$ & 0.150 \\
Item 5 & $\mathbf{0 . 7 1 1}$ & 0.224 \\
Item 6 & $\mathbf{0 . 6 3 0}$ & 0.359 \\
Item 7 & $\mathbf{0 . 7 9 0}$ & 0.196 \\
Item 8 & $\mathbf{0 . 6 9 8}$ & 0.248 \\
Item 9 & $\mathbf{0 . 6 9 5}$ & 0.296 \\
Item 10 & 0.400 & $\mathbf{0 . 6 4 4}$ \\
Item 11 & 0.201 & $\mathbf{0 . 8 1 4}$ \\
\hline
\end{tabular}

Table 3.

Item Distribution Results and Names of Factors

\begin{tabular}{|c|c|c|c|}
\hline $\begin{array}{l}\text { Component/ } \\
\text { Factor }\end{array}$ & $\begin{array}{c}\text { Item } \\
\text { Number }\end{array}$ & Item & Factor \\
\hline \multirow[t]{6}{*}{1} & 4 & I feel thankful towards everyone. & \multirow{6}{*}{$\begin{array}{l}\text { Appreciation to the constant } \\
\text { experience of life. }\end{array}$} \\
\hline & 5 & $\begin{array}{l}\text { As I get older, I feel more capable of } \\
\text { appreciating other people that took part } \\
\text { in my life journey. }\end{array}$ & \\
\hline & 6 & $\begin{array}{l}\text { I feel more capable of appreciating } \\
\text { events that take occur in my life. }\end{array}$ & \\
\hline & 7 & $\begin{array}{l}\text { I feel more capable of appreciating my } \\
\text { current situation. }\end{array}$ & \\
\hline & 8 & $\begin{array}{l}\text { I feel that I spend more time feeling } \\
\text { grateful for something or someone. }\end{array}$ & \\
\hline & 9 & $\begin{array}{l}\text { I feel grateful towards unfortunate } \\
\text { things that happen to me. }\end{array}$ & \\
\hline \multirow[t]{5}{*}{2} & 1 & $\begin{array}{l}\text { There are many things that I should be } \\
\text { grateful for in life. }\end{array}$ & \multirow{5}{*}{$\begin{array}{l}\text { Appreciation towards } \\
\text { individuals that take part in } \\
\text { my life. }\end{array}$} \\
\hline & 2 & $\begin{array}{l}\text { If I had a list of things that I am grateful } \\
\text { for, it would probably be long. }\end{array}$ & \\
\hline & 3 & $\begin{array}{l}\text { When I see the world, I feel that there is } \\
\text { not much to be grateful of* }\end{array}$ & \\
\hline & 10 & $\begin{array}{l}\text { I feel grateful of what the universe has } \\
\text { to offer. }\end{array}$ & \\
\hline & 11 & I feel grateful to God. & \\
\hline
\end{tabular}

One item that was revised from the original GQ-6 is item five, which that states "As I get older, I feel more capable in appreciating other people who took part in my life journey." This is then divided into three items, that is: (1) "As I get older,
I feel more capable of appreciating other people that took part in my life journey.", (2) "I feel more capable of appreciating events that occur in my life.", and "I feel more capable of appreciating my current situation." The items are divided to 
prevent double or multiple meanings. The additional items obtained from the focused group discussions are: (4) "I feel grateful towards unfortunate things that happen to me.", (5) "I feel grateful for what the universe has to offer.", and "I feel grateful to God."

McCullough et al. (2002) defined gratitude as the tendency to acknowledge a positive emotion that arises due to something else or someone else. This definition is not suitable for the results obtained in this research, because the Gratitude Questionnaire (GQ-6) in this research has several additional items; one which states "I feel grateful towards unfortunate things that happen to me." In this regard, gratitude does not emerge from a positive thing matter, but also from unfortunate occasions that one experiences.

In a research conducted by Lambert, Graham, Fincham, and Stillman (2009), gratitude is linked with sense of coherence from positive reframing. Antonovsky (in Lambert et al., 2009) stated that sense of coherence is the belief that life can be managed, is meaningful, and understood. Positive reframing is a process by which unfortunate incidents are seen from a positive standpoint (Lambert et al., 2009). According to Lambert et al. (2009), individuals with a higher level of gratitude are able to use positive reframing to perceive negative events as something more meaningful, as understandable and manageable.

In Indonesian adolescents, gratitude is not only expressed towards other individuals, but also towards the universe and God. This expression is portrayed in item number ten ("I feel grateful of what the universe has to offer") and item eleven ("I feel grateful to God)." In the Gratitude Questionnaire-6 (GQ-6) used in this research, both items are valid and fulfill the criteria of a good item, that leads to it in accordance to the statement by Emmons and McCullough (2003) that stated gratitude can be shown both towards humans and nonhuman (e.g., animals, nature, God).

The reliability test conducted by internal consistency approach based on data which obtained from a group of respondents who were given a one-time attitude scale. The reliability coefficient is seen from the value of Cronbach's alpha. Result of the reliability analysis with Cronbach's alpha coefficient, $\alpha=0.879$ with the coefficient item total correlation of 0.517 until 0.655. This indicates that the Gratitude Questionnaire-6 (GQ-6) is consistent in measuring gratitude of Indonesian adolescent, and the eleven items a fulfill the standards or requirements of a good item.

Validity test was conducted by evaluating the construct validity through a factor analysis approach. The exploratory factor analysis (EFA) shows that the Gratitude Questionnaire-6 (GQ-6) consisted of eleven items and has two underlying factors. The items that belonged to each factor fits the original arrangement and its theoretical construct that had been explored during instrument drafting. The results showed consistency between the EFA results and theoretical construct.

In this research, the Gratitude Questionnaire-6 (GQ-6) consisted of eleven items which form two factors. The exploratory factor analysis (EFA) resulted in two factors: factor one consists of items number 4, 5, 6, 7, 8, 9 and factor two consists of items number 1, 2, 3, 10, 11. Factor one generally depicts the feeling of appreciation towards the constant experience of life experience, and factor two generally depicts the feeling of indivi- 
dual appreciation towards all aspects of life.

The first factor is gratitude as an appreciation towards the constant experience of life. Experience is defined as something one goes through. Gratitude as an appreciation to the constant experience of life means that gratitude is elicited by experienced events or occurences that happens to or is felt by an individual. It is called a constant experience of life because gratitude can and have to be felt in daily life in order for an individual to feel good about positive occurrences and not feel burdened by negative experiences. According to Schimmel (2004) an individual that does not consistently train oneself to express gratitude and appreciation when interacting with others in his or her daily life will struggle to have a sense of gratitude, thus would find it hard to express gratitude sincerely in during (social) interactions, including situations that requires them to express gratitude towards God.

The second factor is gratitude as an appreciation of an individual towards all parts and aspects of life. Appreciation towards the things could also be defined as the feeling of thankful. Parts of life of an individual covers all aspects related to their life, not only towards other individuals but also towards the universe and God. Schwitzer (in McCullough et al., 2003) stated gratitude as a secret of life, the biggest thing in life is to be thankful toward everything. So, as the human being who has learned that thing (to be thankful towards everything) will be able to understand life itself.

The Gratitude Questionnaire-6 (GQ-6) consists of eleven items and consistently measures gratitude in adolescents. The 11 items fall within two factors: gratitude as an appreciation towards the constant experience of life and gratitude as an appreciation towards all aspects of life. This shows conflicting results from previous research. This difference in results is highly correlated with cultural factors.

Gratitude is a character strength that is universal or general, yet the construct of gratitude itself cannot be conceptualized as general or the same in all society or culture, because each culture holds different social norms that will influence how a construct should be understood (Morgan et al., 2014). Moreover, Morgan et al. (2014) explained that the definition and essence of gratitude that is generally similar in all cultures, yet the aspects or elements that builds or constructs gratitude may be different and may change depending on each culture.

\section{Conclusion}

In this research, five items were added into the original Gratitude Questionnaire-6 (GQ-6), resulting in a total of 11 items. The scale of 11 items has good reliability and validity when tested on adolescents. This 11-item gratitude questionnaire consistently measured gratitude in adolescents based on two factors that is, appreciation to the constant experience of life and appreciation towards individuals that take part in one's life.

\section{Suggestions}

Several suggestions can be given based on the results of this research. Future research should conduct confirmatory factor analysis (CFA) to verify the number of factors constructed, whether or not the items already depicts factors that are constructed or the relationship between items and its underlying factors. Seeing the psychometric property of the Gratitude Questionnaire-6 (GQ-6) that consists of 
eleven items, additional respondents should be involved to provide a more representative result.

This research has many limitations, specifically regarding the execution of the focused group discussions. For instance, the researchers did not deliver the discussion materials prior to the discussion, both in printed or through other forms of media. For further research, strengthening the model and procedure of focus group discussion is needed. By having more control in the technical application that occurs in the field, it could obtain more comprehensive data.

\section{References}

Anastasi, A., \& Urbina, S. (1997). Tes psikologi (R. H. Imam, Trans.). Jakarta: Prenhallindo.

Angelia, Y. (2016). Hubungan antara gratitude dengan subjetive well-being pada kelompok pengajian di Masjid Agung Sunda Kelapa. (Unpublished bachelor's thesis). Universitas Mercubuana, Jakarta.

Azwar, S. (1995). Sikap manusia teori dan pengukurannya. Yogyakarta: Pustaka Pelajar.

Azwar, S. (1999). Penyusunan skala psikologi. Yogyakarta: Pustaka Pelajar.

Azwar, S. (2012). Reliabilitas dan validitas. Yogyakarta: Pustaka Pelajar.

Beaton, D. E., Bombardier, C., Guillemin, F., \& Ferraz, M. B. (2000). Guidelines for the process of cross-cultural adaptation of self-report measures. Spine, 25(24), 3186-3191. doi: 10.1097/00007632-200012150-00014

Chen, L. H., Chen, M. Y., Kee, Y. H., \& Tsai, Y. M. (2009). Validation of the gratitude questionnaire (GQ) in Taiwanese undergraduate students.
Journal of Happiness Studies, 10(6), 655664. doi: 10.1007/s10902-008-9112-7

Emmons, R. A., \& McCullough, M. E. (2003). Counting blessings versus burdens: An experimental investigation of gratitude and subjective well-being in daily life. Journal of Personality and Social Psychology, 84(2), 377-389. doi: 10.1037/0022$\underline{3514.84 .2 .377}$

Froh, J. J., Bono, G., \& Emmons, R. (2010). Being grateful is beyond good manners: Gratitude and motivation to contribute to society among early adolescents. Motivation and Emotion, 34(2), 144-157. doi: 10.1007/s11031010-9163-Z

Froh, J. J., Fan, J., Emmons, R. A., Bono, G., Huebner, E. S., \& Watkins, P. (2011). Measuring gratitude in youth: Assessing the psychometric properties of adult gratitude scales in children and adolescents. Psychological Assessment, 23(2), 311-324. doi: $\underline{10.1037 / \mathrm{a} 0021590}$

Froh, J. J., Yurkewicz, C., \& Kashdan, T. B. (2009). Gratitude and subjective wellbeing in early adolescence: Examining gender differences. Journal of Adolescence, 32(3), 633-650. doi: $\underline{10.1016 / j . a d o l e s c e n c e .2008 .06 .006}$

Gudmundsson, E. (2009). Guidelines for translating and adapting psychological instruments. Nordic Psychology, 61(2), 29-45. doi: 10.1027/1901-2276.61.2.29

Hafiz, M. (2018). Peran kebersyukuran terhadap work engagement pada pegawai Aparatur Sipil Negara (ASN) di Kabupaten Sintang Provinsi Kalimantan Barat. (Unpublished bachelor's thesis). Faculty of Psychology and Social Cultural Sciences, Universitas Islam Indonesia, Yogyakarta.

Kaplan, R. M., \& Saccuzzo, D. P. (2005). 
Psychological testing: Principles, applications, and issues (6th ed.). USA: Thomson Wadsworth.

Lambert, N. M., Graham, S. M., Fincham, F. D., \& Stillman, T. F. (2009). A changed perspective: How gratitude can affect sense of coherence through positive reframing. Journal of Positive Psychology, 4(6), 461-470. doi: $\underline{10.1080 / 17439760903157182}$

Langer, Á. I., Ulloa, V. G., Aguilar-Parra, J. M., Araya-Véliz, C., \& Brito, G. (2016). Validation of a Spanish translation of the Gratitude Questionnaire (GQ-6) with a Chilean sample of adults and high schoolers. Health and Quality of Life Outcomes, 14(1), 1-9. doi: 10.1186/s12955-016-0450-6

McCullough, M. E., Emmons, R. A., \& Tsang, J. A. (2002). The grateful disposition: A conceptual and empirical topography. Journal of Personality and Social Psychology, 82(1), 112-127. doi: 10.1037/0022$\underline{3514.82 .1 .112}$

McCullough, M. E., Emmons, R. A., \& Tsang, J. A. (2003). The Assessment of Gratitude. In C. Snyder \& S. J. Lopez (Eds.), Positive psychological assessment: A handbook of models of measures. Washington, DC: American Psychological Association.

Morgan, B., Gulliford, L., \& Kristjánsson, K. (2014). Gratitude in the UK: A new prototype analysis and a cross-cultural comparison. Journal of Positive Psychology, 9(4), 281-294. doi: $\underline{10.1080 / 17439760.2014 .898321}$

Naito, T., \& Washizu, N. (2015). Note on cultural universals and variations of gratitude from an East Asian point of view.
International Journal of Behavioral Science, 10(2), 1-8.

Neto, F. (2007). Forgiveness, personality and gratitude. Personality and Individual Differences, 43(8), 2313-2323. doi: 10.1016/j.paid.2007.07.010

Oriza, I. I. D., \& Menaldi, A. (2010). Validasi skala bersyukur pada orang Indonesia. Proceeding Konferensi Nasional II Ikatan Psikologi Klinis Himpsi: Intervensi Psikologis untuk Meningkatkan Kualitas Hidup Masyarakat Indonesia. Yogyakarta: Ikatan Psikologi Klinis - Himpsi.

Osterlind, S. J. (2010). Modern measurement theory, principle, and applications of mental appraisal (2nd ed.). United States of America: Pearson Education.

Sarwono, S. W. (2007). Psikologi remaja. Jakarta: Raja Grafindo Persada.

Schimmel, S. (2004). Gratitude in Judaism. In R. A. Emmons \& M. E. McCullough (Eds.), Series in affective science. The psychology of gratitude. USA: Oxford University Press.

Suryabrata, S. (1999). Pengembangan alat ukur psikologis. Jakarta: Directorate General of Higher Education, Ministry of Education and Culture Republic of Indonesia.

Tsang, J. A. (2006). Gratitude and prosocial behaviour: An experimental test of gratitude. Cognition and Emotion, 20(1), 138-148.

doi: $\underline{10.1080 / 02699930500172341}$

Wang, D., Wang, Y. C., \& Tudge, J. R. H. (2015). Expressions of gratitude in children and adolescents: Insights from China and the United States. Journal of Cross-Cultural Psychology, 46(8), 1039-1058. doi: $\underline{10.1177 / 0022022115594140}$ 


\section{ADAPTATION OF GRATITUDE QUESTIONNAIRE-6 (GQ-6)}

Yüksel, A., \& Oğuz Duran, N. (2012). Turkish adaptation of the gratitude questionnaire. Egitim Arastirmalart-
Eurasian Journal of Educational Research, 46(46), 199-216. 